\title{
Hepatitis B virus replication is upregulated in proliferated peripheral blood lymphocytes
}

\author{
QIN YAN, YING-HUA LAN, YAN-XIN HUANG, RONG-SHAN FAN, \\ LAN LIU, SHU-PENG SONG and YONG-GUO LI

\begin{abstract}
Department of Infectious Diseases, The First Affiliated Hospital of Harbin Medical University, Harbin, Heilongjiang 150001, P.R. China
\end{abstract}

Received March 20, 2015; Accepted January 26, 2016

DOI: $10.3892 / \mathrm{mmr} .2016 .4973$

\begin{abstract}
Increasing evidence indicates that the hepatitis B virus (HBV) replicates in peripheral blood mononuclear cells (PBMCs), but at a low level. The present study aimed to establish a reliable and sensitive method that effectively detects HBV viral products for monitoring antiviral therapy, organ transplantation screening, and diagnosing occult HBV infection. In the present study, PBMCs (obtained from six healthy volunteers) were inoculated with $\mathrm{HBV}$, and cultured with phytohemagglutinin (PHA) and interleukin-2 (IL-2) to stimulate cell proliferation. PBMCs were harvested, and quantitative detection of HBV DNA in cell suspension and intracellular hepatitis B surface antigen ( $\mathrm{HBsAg}$ ) was conducted on days 0 , 1, 6 and 12, respectively. In situ hybridization, immunohistochemistry and reverse transcription-polymerase chain reaction (RT-PCR) were performed to analyze the HBV infection. The results demonstrated that HBV DNA increased concurrently with proliferation of PBMCs isolated from three of six healthy volunteers, and the mean number of PBMCs on day 12 was 13.61 times higher than the initially seeded cell number $(\mathrm{P}<0.01)$. The mean copies of HBV DNA at day 12 were 2.98 times higher compared with initial levels $(\mathrm{P}<0.05)$. Furthermore, intracellular HBsAg levels increased concurrently with proliferation of PBMCs in one group of cultured PBMCs, which was accompanied by increased HBV DNA levels. In addition, HBV nucleic acids were detected in PBMCs using in situ hybridization. Intracellular HBsAg was observed in PBMCs and HBV RNA was also detected by RT-PCR. The present study demonstrated that HBV replicates in proliferating PBMCs, which were induced by PHA and IL-2. This method offers a novel investigative tool to detect HBV infection in PBMCs and to monitor the course of HBV infection.
\end{abstract}

Correspondence to: Dr Yong-Guo Li, Department of Infectious Diseases, The First Affiliated Hospital of Harbin Medical University, 23 Post Street, Nangang, Harbin, Heilongjiang 150001, P.R. China E-mail: liyongguodoctor@163.com

Key words: hepatitis B virus, peripheral blood mononuclear cell, phytohemagglutinin, replication

\section{Introduction}

The hepatitis B virus (HBV) is a hepatotropic virus that predominantly infects and replicates in hepatocytes. However, previous studies have demonstrated that HBV is present in peripheral blood mononuclear cells (PBMCs) (1-3), which are considered to be a reservoir contributing to chronic HBV infection $(4,5)$. The risk for HBV transmission by infected PBMCs has also been demonstrated. For example, HBV-infected mothers may transmit the HBV infection to newborns during the perinatal period (6) and livers from donors who were hepatitis B surface antigen (HBsAg)-negative, but hepatitis B core antibody (anti-HBc)-positive may transmit the HBV infection to recipients following liver transplantation (7). HBV infection may occur as a result of blood transfusion and hemodialysis using blood that is contaminated with $\operatorname{HBV}(8,9)$, in addition to immunosuppressant therapy-induced hepatitis B reactivation (10). All of these transmissions are closely associated with HBV infection in PBMCs. Thus, the detection of HBV infection in PBMCs is considered to be clinically significant.

HBV replication in PBMCs is at a low level (5) and current methods, including polymerase chain reaction (PCR), are not sensitive enough to detect the minute quantities of viral products (11). It is particularly difficult to detect covalently closed circular DNA (cccDNA), which functions as a template for transcription and a marker for HBV replication. Currently, it is unclear whether HBV replicates in PBMCs (12-16) and whether the virus readily infects PBMCs (17) due to a lack of cccDNA detection methods. Thus, further studies are required to develop more sensitive methods to detect small quantities of viral products in PBMCs, and eventually determine whether HBV infects and replicates in PBMCs.

El-Awady et al (18) demonstrated that hepatitis C virus (HCV) infects PBMCs, and that phytohemagglutinin (PHA)-induced proliferation of PBMCs increases HCV replication. Furthermore, it was reported that woodchuck HBV replication is upregulated in PBMCs with mitogen stimulation (19-21). Our previous studies also suggested that HBV gene expression is increased following expansion of bone marrow hematopoietic stem cells isolated from chronic hepatitis B patients, via a non-specific mitogen stimulus $(22,23)$. Based on these findings, the aim of the present study was to establish a method to increase HBV replication in PBMCs via mitogen stimulation in vitro. It was 
demonstrated that the detection of HBV DNA and HBsAg in PBMCs is markedly improved following in vitro mitogen treatment. Thus, this method may be used for evaluating antiviral treatment responses, organ transplantation screening and for the diagnosis of occult hepatitis B.

\section{Materials and methods}

Preparation of PBMCs. PBMCs were obtained from six healthy volunteers (two males and four females; age, $32.3 \pm 10.7$ years). All participants were negative for hepatitis A, C, D, E, and HIV antibodies, and negative for hepatitis B serological markers and HBV DNA. Participants exhibited normal alanine transaminase levels and were not vaccinated against HBV. The present study was approved by the Ethics Committee of the Institutional Review Board of The First Affiliated Hospital of Harbin Medical University (Harbin, China). The experimental protocol was established, according to the ethical guidelines of the Helsinki Declaration. Written informed consent was obtained from individual participants.

PBMCs were separated from $20 \mathrm{ml}$ ethylenediaminetetraacetic acid (EDTA)-treated blood by Ficoll density gradient centrifugation (Tianjin Haoyang Biological Technology Co., Ltd., Tianjin, China) at $1,000 \mathrm{x}$ g for $20 \mathrm{~min}$ at $20^{\circ} \mathrm{C}$, resulting in a yield of $\sim 6.32 \pm 2.11 \times 10^{6}$ cells $/ \mathrm{ml}$ blood. The cells were washed three times with phosphate-buffered saline (PBS) prior to seeding into culture wells.

In vitro infection of PBMCs with $H B V$ and stimulation with mitogen. PBMCs were seeded in 24-well plates at a final concentration of $10^{5}$ cells $/ \mathrm{ml}$ with $0.95 \mathrm{ml}$ RPMI-1640 (Hyclone; GE Healthcare Life Sciences, Logan, UT, USA) and $0.05 \mathrm{ml}$ HBV-positive serum (HBV DNA $10^{7} \mathrm{IU} / \mathrm{ml}$, genotype C) filtered through a Millex-GP $0.22-\mu \mathrm{m}$ filter (EMD Millipore, Billerica, MA, USA). The culture medium was supplemented with $10 \%$ fetal calf serum (Hyclone; GE Healthcare Life Sciences). Cells were stimulated by PHA (Sigma-Aldrich, St. Louis, MO, USA) with a final concentration of $5 \mu \mathrm{g} / \mathrm{ml}$ and interleukin (IL)-2 (Sigma-Aldrich) with a final concentration of $20 \mathrm{U} / \mathrm{ml}$. Plates were incubated at $37^{\circ} \mathrm{C}$ and $5 \% \mathrm{CO}_{2}$ for 12 days. This experiment was repeated six times with PBMCs. Three wells of cells were harvested at day $0,1,6$ and 12. The number of viable cells was estimated by $0.04 \%$ Trypan Blue exclusion (Sigma-Aldrich). A mean of the cell numbers of three wells was used for calculation at each time-point. Cells were stored at $-80^{\circ} \mathrm{C}$ for further analysis.

Quantification of $H B V$ DNA within PBMCs. DNA was isolated from $1 \mathrm{ml}$ cell suspension using the Cobas AmpliPrep automated extractor (Roche Diagnostics GmbH, Mannheim, Germany), according to the manufacturer's protocols. HBV DNA was quantitatively detected from the isolated DNA prep using a Cobas TaqMan 48 analyzer (version 3.3; Roche Diagnostics $\mathrm{GmbH}$ ). Data were analyzed with Amplilink software (Roche Diagnostics GmbH). Cobas AmpliPrep/Cobas TaqMan HBV test kit (version 2.0) was used to measure the lower limit of detection with primers located in the pre-C/C highly conserved region (Table I) (11). The mean of the copy numbers from three detection wells indicated that $20 \mathrm{IU} / \mathrm{ml}$ was the lower limit of detection.
Detection of HBV RNA isolated from PBMCs by reverse transcription (RT)-PCR. PBMCs that were cultured as described above were harvested at day $0,1,6$ and 12 , with a cell density of $1.0 \times 10^{5}, 1.8 \times 10^{5}, 5.8 \times 10^{5}$, and $1.1 \times 10^{6}$ cells $/ \mathrm{ml}$, respectively. PBMCs were washed three times with PBS. Total cellular RNA was extracted using $1 \mathrm{ml}$ TRIzol reagent (Invitrogen; Thermo Fisher Scientific, Inc., Waltham, MA, USA), $200 \mu 1$ chloroform (Tianjin Haoyang Biological Technology Co., Ltd.), $0.5 \mathrm{ml}$ isopropyl alcohol and $1 \mathrm{ml}$ ethanol (75\%; both Tianjin Fuyu Chemical Co., Tianjin, China). Complementary DNA (cDNA) was synthesized using Qiagen OneStep RT-PCR kit (Qiagen GmbH, Hilden, Germany). The cDNA primer sequence within the $\mathrm{S}$ region was used as previously described (Table I; Boster Biological Technology, Ltd., Wuhan, China) (24). Glyceraldehyde-3-phosphate dehydrogenase (GAPDH) served as an internal reference (Table I; Boster Biological Technology, Ltd.). RT was conducted on a Mastercycler (Eppendorf AG Hamburg, Germany) at $60^{\circ} \mathrm{C}$ for $1 \mathrm{~min}, 42^{\circ} \mathrm{C}$ for $10 \mathrm{~min}, 50^{\circ} \mathrm{C}$ for $30 \mathrm{~min}$, and $95^{\circ} \mathrm{C}$ for $15 \mathrm{~min}$. The cDNA was amplified as follows: 40 Cycles of $94^{\circ} \mathrm{C}$ for $30 \mathrm{sec}, 56^{\circ} \mathrm{C}$ for $30 \mathrm{sec}, 72^{\circ} \mathrm{C}$ for $1 \mathrm{~min}$; and $72^{\circ} \mathrm{C}$ for $10 \mathrm{~min}$. PCR products (length, $452 \mathrm{bp}$ ) were stored at $4^{\circ} \mathrm{C}$ prior to visualization via $1 \%$ agarose electrophoresis. Electrophoresis was performed using $10 \mu \mathrm{l} \mathrm{cDNA}$, $6 \mu$ DNA marker (D2000; Tiangen Biochemical Technology, Co., Ltd., Tiangen, China) and loading buffer (Takara Biotechnology, Co., Ltd., Dalian, China) at $110 \mathrm{~V}$ for $30 \mathrm{~min}$. Images were captured using a GL-3120 Compact Desktop UV Transmissometer (Korea Biotech Co., Ltd., Seoul, Korea) software.

In situ hybridization detection of HBV DNA in PBMCs. The $\mathrm{HBV}$-inoculated PBMCs that were cultured for 12 days, were harvested and washed three times with PBS. Hepatitis B virus nucleic acid in situ hybridization kit (Tianjin Haoyang Biological Technology Co., Ltd.) was used to detect HBV DNA on PBMC slides, according to the manufacturer's protocols. Hybridization was conducted in a hybrid oven (Abbott Stat Spin ${ }^{\circledR}$; Abbott Laboratories, Chicago, IL, USA). The hybridization signal was generated with fluorescein isothiocyanate (FITC) fluorescent dye. Hybridization solution containing no specific probe served as a negative control, whereas HepG2.2.15 cells, which were gifted from Professor Hong Ren (Chongqing Medical University, Yuzhong, China), served as a positive control. The HBV probe sequence (Tianjin Haoyang Biological Technology Co., Ltd.) was derived from a highly conserved region that is located in the overlapped $\mathrm{P}$ and pre-C open reading frame (Table I). Slides were examined under a Nikon Eclipse TS100 80i microscope (Nikon Corporation, Tokyo, Japan) and Olympus BX53 fluorescence microscope (Olympus Corporation, Tokyo, Japan).

Quantification of HBsAg in PBMCs. The same PBMCs from the three wells described above were harvested at day 0,1 , 6 and 12 and washed three times with PBS. The cells were lysed with 10 mM Tris-Hcl (Sangon Biotech Co., Ltd., Shanghai, China) and 1\% Triton X-100 (Solarbio Science \& Technology Co., Ltd., Beijing, China) and intracellular HBsAg was quantified using an Architect HBsAg assay (Abbott Laboratories), according to the manufacturer's protocols. The lowest limit of detection was $0.00-0.05 \mathrm{IU} / \mathrm{ml}$. 
Table I. HBV primer and probe sequences.

\begin{tabular}{lcllc}
\hline Primer & $\begin{array}{c}\text { Primer set } \\
\text { designation }\end{array}$ & Polarity & \multicolumn{1}{c}{ Sequences (5' to 3') } & $\begin{array}{c}\text { Position } \\
\left(5^{\prime} \text { to 3') }\right.\end{array}$ \\
\hline Quantitative PCR & Pre-C/C & $\begin{array}{l}\text { Sense } \\
\text { Sense }\end{array}$ & $\begin{array}{l}\text { ACATAAGAGGACTCTTGGAC } \\
\text { TACTTCAAAGACTGTGTGTTA }\end{array}$ & $1652-1671$ \\
& & Antisense & CCCACCTTATGAGTCCAAGG & $1704-1723$ \\
Reverse transcription PCR & $\mathrm{S}$ & Sense & CTTCATCCTGCTGCTATGCC & $2512-2439$ \\
& & Antisense & CAACGTTTGTTTATTAGGGT & $406-425$ \\
& \multirow{2}{*}{ GAPDH } & Sense & ACCACAGTCCATGCCATCAC & $857-835$ \\
& & Antisense & TCCACCACCCTGTTGCTGTA & \\
HBV probe & P/pre-C & Sense & TAGAAGAAGAACTCCCTCGCCTCGCAGACG & \\
& & Antisense & CAGAGGCAAATCAGGTAGGAGCGGGAGCAT & \\
\hline
\end{tabular}

HBV, hepatitis B virus; PCR, polymerase chain reaction; GAPDH, glyceraldehyde-3-phosphate dehydrogenase.
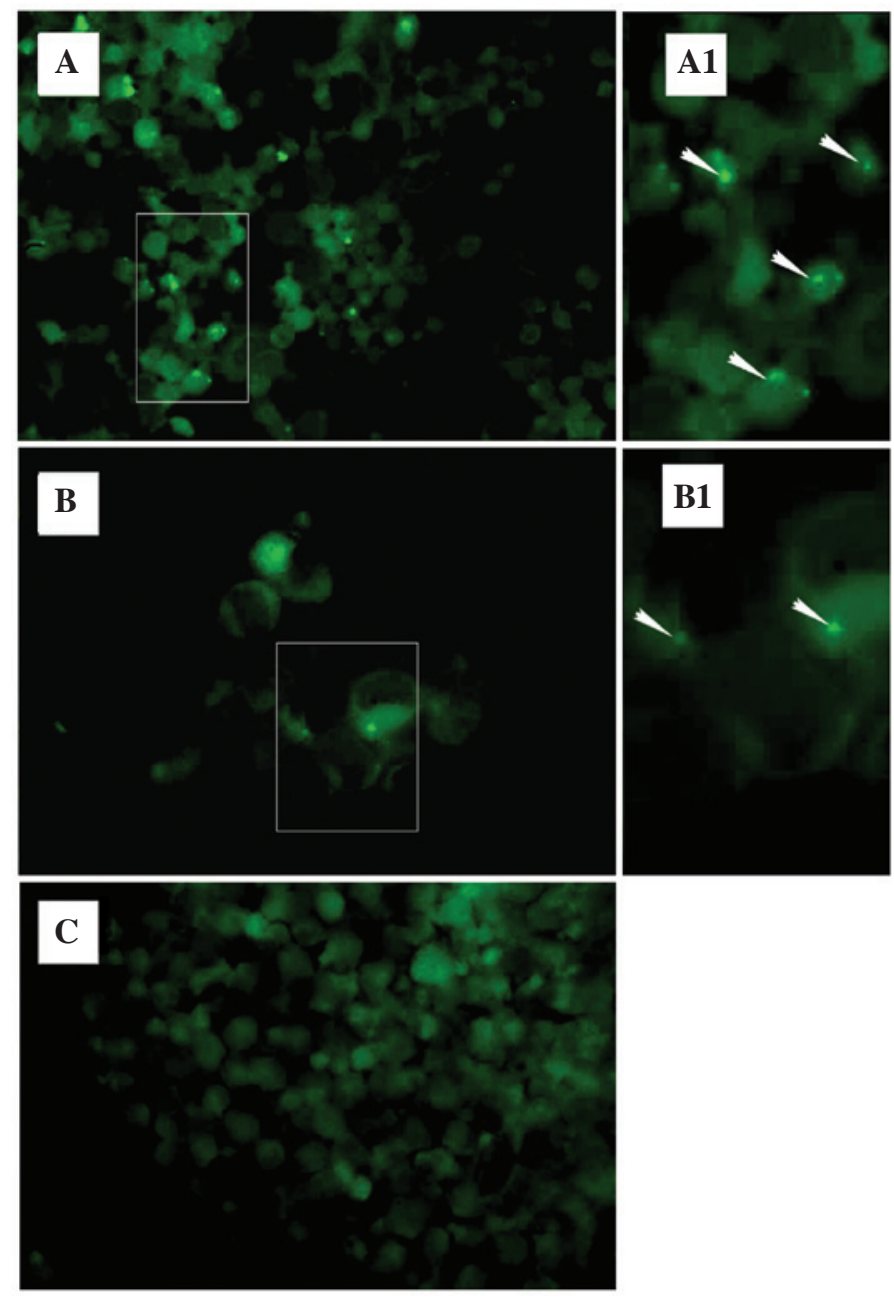

Figure 1. Detection of HBV nucleic acid in PBMCs by in situ hybridization. PBMCs were co-cultured with HBV for 12 days, harvested and washed three times with phosphate-buffered saline prior to hybridization. (A) Positive signals for fluorescein isothiocyanate fluorescence were detected within PBMCs. (A1) The boxed section was magnified $2 \mathrm{X}$ and positive signals are indicated by the arrows. (B) Fluorescence signals were also detected in HepG2.2.15 cells (positive control). (B1) The boxed section was magnified $2 \mathrm{X}$ and positive signals are indicated by the arrows. (C) No fluorescence signal was detected in the hybridization solution without a probe (negative control). Magnification, x40. HBV, hepatitis B virus; PBMC, peripheral blood mononuclear cell.

Immunohistochemistry of HBsAg in PBMCs. At day 12, the cultured PBMCs were collected, washed three times with PBS, and smeared onto slides. Immunostaining of HBsAg was performed using an Immunostain SP kit (Beijing Zhongshan Jingqiao Biotechnology, Co., Ltd., Beijing, China). A mouse monoclonal antibody against HBsAg 

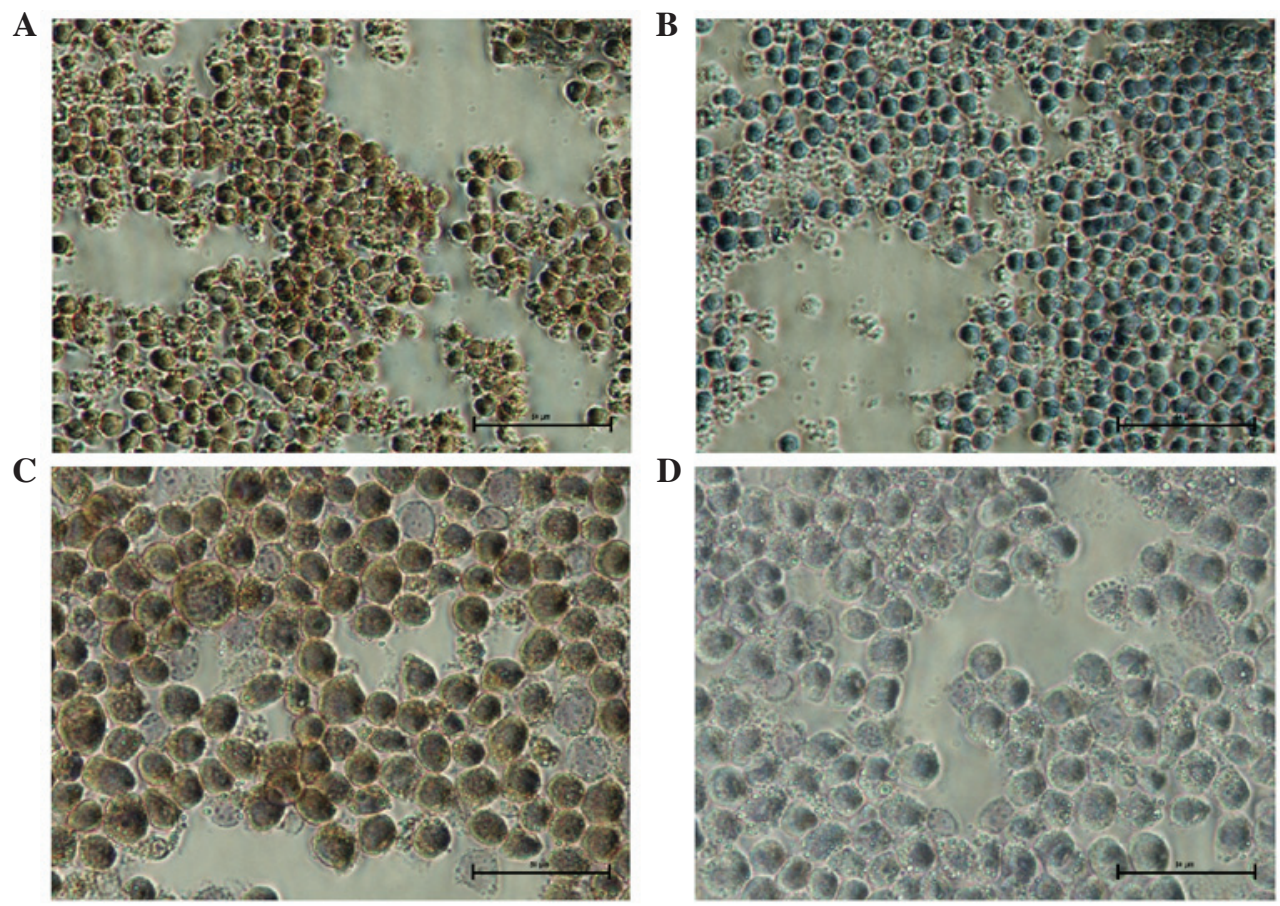

Figure 2. Detection of HBsAg in the cytoplasm of PBMCs by immunohistochemical staining. PBMCs co-cultured with hepatitis B virus for 12 days were harvested and washed three times with PBS. (A) The positive HBsAg (brown staining) was located in the cytoplasm. (B) No HBsAg was detected in the negative control in which the mouse anti-HBsAg was replaced with PBS. (C) HepG2.2.15 cells served as a positive control and the cytoplasm was stained brown. (D) Mouse anti-HBsAg was replaced with PBS and served as the negative control for HepG2.2.15 staining. Magnification, x40. HBsAg, hepatitis B surface antigen; PBMC, peripheral blood mononuclear cell; PBS, phosphate-buffered saline.

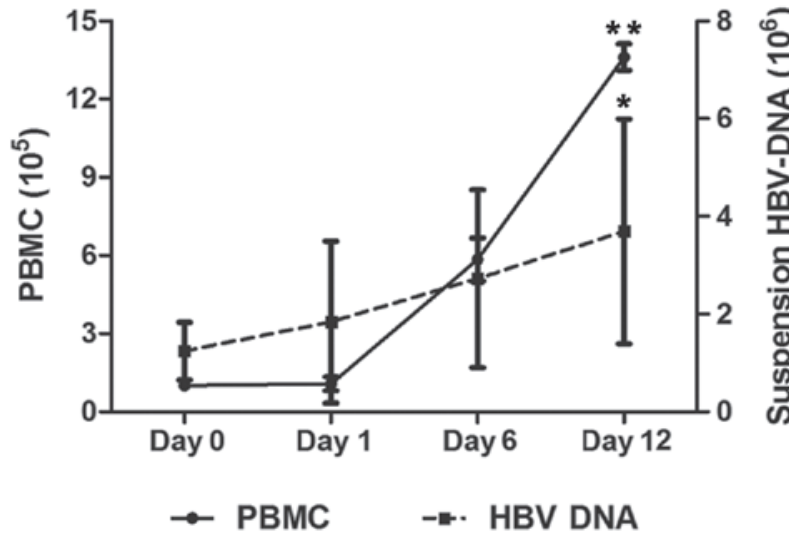

Figure 3. Quantification of HBV DNA in PBMCs. PBMCs were co-cultured with HBV, and stimulated with phytohemagglutinin and interleukin-2. Quantification of HBV DNA was performed in PBMC suspensions isolated at day $0,1,6$ and 12 . The initial number of cells was $1.0 \times 10^{5} / \mathrm{ml}$. The mean PBMC number from three cases at day 12 was 13.61 times higher than the initial density $\left({ }^{* *} \mathrm{P}<0.01\right)$. The results demonstrated that HBV DNA load increased with cell proliferation in three of six PBMCs isolates. The mean load of HBV DNA was increased by 2.98 times on day 12 compared with the initial load ("P<0.05). HBV, hepatitis B virus; PBMC, peripheral blood mononuclear cell.

(1:50; ZM-0122; Beijing Zhongshan Jingqiao Biotechnology, Co., Ltd.) was used as the primary antibody, whereas a goat anti-mouse IgG without dilution (ZDR-5117; Beijing Zhongshan Jingqiao Biotechnology, Co., Ltd.) was used as the secondary antibody. The reaction was subsequently visualized using 3,3'-diaminobenzidine (Beijing Zhongshan Jingqiao Biotechnology, Co., Ltd.). HepG2.2.15 cells served as a positive control.
Statistical analysis. All statistical analyses was performed using SAS 9.2 statistical analysis software (SAS Institute, Cary, NC, USA). Data are expressed as the mean \pm standard error of the mean. The mixed-effects model was used to analyze the changes in cell proliferation and viral replication with culture time. The same analysis was also used to analyze the association between cellular proliferation and viral replication subsequent to adjusting for the time factor. $\mathrm{P}<0.05$ was considered to indicate a statistically significant difference.

\section{Results}

HBV DNA was detected in PBMCs by in situ hybridization. The PBMCs inoculated with HBV and cultured for 12 days demonstrated a positive signal following hybridization with an FITC-labeled probe. A similar fluorescence signal was also detected in HepG2.2.15 cells. No fluorescence signal was observed in the PBMCs that were hybridized without the specific probe (Fig. 1).

HBsAg was detected in PBMCs by immunohistochemistry. The PBMCs were stained with the HBsAg-specific antibody. The immunohistochemistry staining demonstrated the presence of HBsAg in the cytoplasm of PBMCs that were harvested at day 12 . The same staining pattern was detected in HepG2.215 cells, however, it was absent in the negative control cells (Fig. 2).

Levels of $H B V D N A$ were increased in proliferated PBMCs induced by PHA and IL-2 in vitro. HBV DNA levels in the 


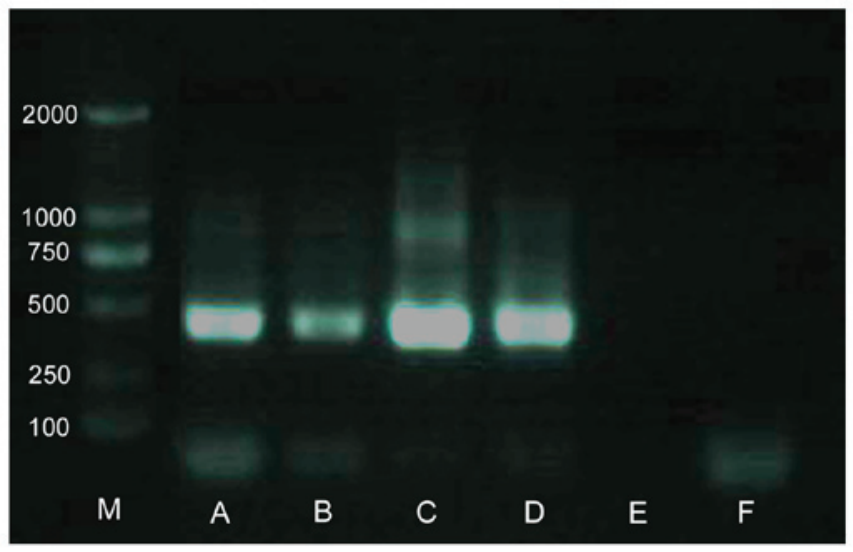

Figure 4. Hepatitis B virus RNA in PBMCs detected by reverse transcription-PCR. PBMCs were washed three times with PBS following harvesting at day $0,1,6$, and 12. Expected PCR band (403 bp) was not detected until days 6 and 12. Lane M, marker DL (2,000 bp); lane A, template of PBMCs at day 6; lane B, GAPDH internal reference (452 bp); lane C, PBMCs at day 12 lane D, GAPDH internal reference; lane E, negative control by replacing PCR mix with PBS; lane F, negative control using PBS as the template. PBMC, peripheral blood mononuclear cell; PCR, polymerase chain reaction; PBS, phosphate-buffered saline.

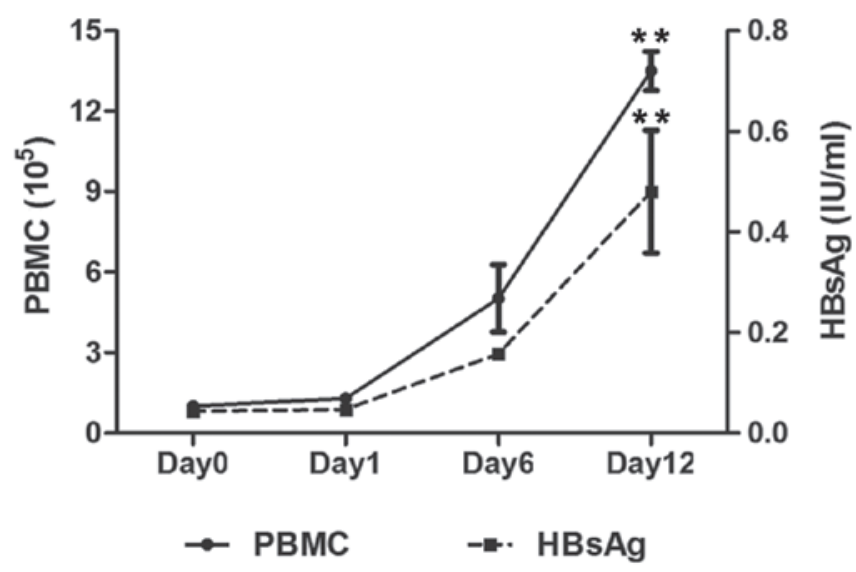

Figure 5. Quantification of HBsAg within PBMCs. HBsAg was detected in three PBMC cultures in which hepatitis B DNA replication increased as proliferation of PBMCs increased. Cells were harvested and lysed for HBsAg detection. The intracellular HBsAg level was increased significantly with cell proliferation in one PBMC culture. ${ }^{* *} \mathrm{P}<0.01$. HBsAg, hepatitis B surface antigen; PBMC, peripheral blood mononuclear cell.

PBMC suspension isolated from three of six healthy volunteers were increased with the proliferation of PBMCs induced by PHA and IL-2. The mean PBMC number isolated from the three cases at day 12 was expanded by 13.61 times compared with the initially seeded density $(\mathrm{P}<0.01)$. The mean load of HBV DNA at day 12 was increased by 2.98 times from the initial level $(\mathrm{P}<0.05)$. However, the correlation between the proliferation of PBMCs and the increase in viral replication was not identified as statistically significant ( $P>0.05$; Fig. 3 ).

HBV RNA was detected in PBMCs by RT-PCR. To investigate whether HBV genes are transcribed in the inoculated PBMCs, HBV RNA transcripts were analyzed by RT-PCR. No PCR amplicon was detected in PBMCs harvested until days 6 and 12. The HBV RNA level was higher on day 12 than on day 6, and the increase of HBV RNA transcription was associated with an increase in HBV DNA level. Negative controls replacing cDNA with PBS, and the PCR mix with PBS, did not demonstrate any effect. GAPDH served as an internal RT-PCR control (Fig. 4).

HBsAg levels increase with PBMC amplification. Intracellular HBsAg was quantitatively determined and increased HBV DNA replication was only detected in one of the three PBMC cultures. Furthermore, the HBsAg level increased as the proliferation of PBMCs increased. Intracellular HBsAg was $0.043 \pm 0.0047 \mathrm{IU} / \mathrm{ml}$ at day 0 and was increased to $0.48 \pm 0.12 \mathrm{IU} / \mathrm{ml}$ (Fig. 5) at day 12 .

\section{Discussion}

PBMCs consist of various types of immune cell, including $\mathrm{T}$ and $\mathrm{B}$ lymphocytes, macrophages and natural killer cells. These cells circulate in the blood to fight infection and travel to different organs to actively engage the immune response. It has been suggested that PBMCs may be infected with HBV. $\mathrm{HBV}$-infected PBMCs compromise the immune response of the host and potentially facilitate the persistence of HBV infection $(25,26)$. However, there is no robust method for detecting HBV infection and replication in PBMCs, which may be due to the HBV infection presenting at a low level in PBMCs. The proliferation of PBMCs is promoted by certain non-specific mitogens, which may assist effective detection of HBV replication. In the present study, PBMCs were inoculated with $\mathrm{HBV}$ in vitro, then stimulated with PHA and IL-2, and cultured for 12 days. The levels of HBV DNA and HBsAg were quantified at different time-points. HBV DNA was detected in PBMC suspensions that were isolated from three of six donors, and it was observed that the HBV DNA levels increased in a time-dependent manner. In addition, intracellular $\mathrm{HBsAg}$ was detected only in one group of cultured PBMCs that also demonstrated the most marked increase in HBV DNA levels. These findings suggest that HBV infects PBMCs, and the infected PBMCs induce HBV replication. Furthermore HBV DNA replication was increased with active cell proliferation. Similar observations were reported by Budkowska et al (17), no detectable cccDNA was observed when PBMCs were co-cultured with a HBV binding factor-digested virus that modified the structure of the envelope proteins and enhanced the capacity of HBV to bind and enter into PBMCs. However, the HBV DNA signal did not decline over time in the cell culture (if there is no virus replication in PBMCs, a progressive reduction of HBV products would be expected). Furthermore, additional evidence supporting HBV replication was generated in the present study; HBV nucleic acid, HBsAg and HBV RNA were detected in PBMCs by in situ hybridization, immunohistochemical staining and RT-RCR, respectively.

Various methodological approaches have previously been used to investigate HBV infection in PBMCs. The present study optimized experimental procedures and our findings demonstrated that cell number influences HBV replication in PBMCs. Once the cell number underwent proliferation under stimulation, the HBV DNA level became increasingly detectable, suggesting that the HBV DNA did replicate, otherwise HBV DNA copies would have been diluted out due to multiple 
cycles of cell division. Previous studies cultured PBMCs for 7 days (16,25-27). However, the present study prolonged PBMC culture to the logarithmic phase to ensure maximum proliferation was reached. Secondly, to ascertain HBV replication in PBMCs, the current study investigated the kinetics of HBV DNA level over time, which was different from the previous studies where the detection of $\mathrm{HBV}$ infection was performed at a single time-point $(16,22)$. The present study improved the procedures for detecting particularly low levels of viral replication.

Southern blotting is the classic method for detecting cccDNA in infected liver tissues, it is specific and reliable, however, it is not sensitive enough to detect low levels of cccDNA (28), and, thus, is not suitable for detecting cccDNA in PBMCs. The results from the present study indicated for the first time, to the best of our knowledge, that HBV was present in PBMCs and that it replicated at particularly low levels. This was supported by the evidence of detectable HBV RNA, which had to be transcribed from the cccDNA template. The results of the current study suggest that mitogen stimulation of infected PBMCs may upregulate viral replication and increase detectability of HBV infection that otherwise may be missed due to the low level of HBV DNA in PBMCs. This procedure may also improve diagnosis of the HBV occult infection, serve as an effective screening tool for organ transplant donors, and assess the efficacy of antiviral therapy. Limitations of the present study were that the PBMCs were provided by individual donors, which may have resulted in certain variations and that the efficiency of HBV inoculation in PBMCs may have affected detection and replication of the HBV infection.

HBV reactivation in PBMCs has been reported following liver transplantation, immunosuppression treatment and chemotherapy $(10,29,30)$. Results from the present study support the hypothesis that HBV may be harbored in PBMCs without being recognized as targets by immune effectors $(31,32)$. Once division of PBMCs is activated by mitogen stimulation, the resulting proliferative PBMCs may facilitate productive virus replication and lead to the reactivation of latent infection to a relatively high level for detection (26). However, further investigations are required to validate the findings of the present study.

In conclusion, the current study demonstrated that HBV infects PBMCs, and HBV replication is upregulated in mitogen-stimulated PBMCs. As HBV DNA in extrahepatic tissues is usually at a particularly low level, ex vivo stimulation of PBMCs using the conditions established in the present study may improve detection of HBV occult infection, and enable more effective treatment.

\section{Acknowledgements}

The present study was supported by the National Key Technologies Research and Development Program of China (grant nos. 2008ZX10002-006 and 2012ZX10002007) and the National Natural Science Foundation of China (grant no. 30571638).

\section{References}

1. Cabrerizo M, Bartolomé J, Caramelo C, Barril G and Carreno V: Molecular analysis of hepatitis B virus DNA in serum and peripheral blood mononuclear cells from hepatitis B surface antigen-negative cases. Hepatology 32: 116-123, 2000
2. Coffin CS, Mulrooney-Cousins PM, Peters MG, van Marle G, Roberts JP, Michalak TI and Terrault NA: Molecular characterization of intrahepatic and extrahepatic hepatitis B virus (HBV) reservoirs in patients on suppressive antiviral therapy. J Viral Hepat 18: 415-423, 2011

3. Michalak TI, Pasquinelli C, Guilhot S and Chisari FV: Hepatitis B virus persistence after recovery from acute viral hepatitis. J Clin Invest 94: 907, 1994.

4. Mazet-Wagner AA, Baclet MC, Loustaud-Ratti V, Denis F and Alain S: Real-time PCR quantitation of hepatitis B virus total DNA and covalently closed circular DNA in peripheral blood mononuclear cells from hepatitis B virus-infected patients. J Virol Methods 138: 70-79, 2006.

5. Torii N, Hasegawa K, Joh R and Hayashi N: Configuration and replication competence of hepatitis B virus DNA in peripheral blood mononuclear cells from chronic hepatitis B patients and patients who have recovered from acute self-limited hepatitis. Hepatol Res 25: 234-243, 2003.

6. Han XB, Yue YF, Bai GQ, Li SH and Shi ZY: Clinical significance of detecting neonatal peripheral blood mononuclear cells infected by HBV. Zhonghua Er Ke Za Zhi 43: 434-437, 2005 (In Chinese)

7. Kim HY, Choi JY, Park CH, Song MJ, Jang JW, Chang UI, Bae SH, Yoon SK, Han JY and Kim DG: Adult living donor liver transplantation using hepatitis B core antibody-positive grafts in Korea, a hepatitis B-endemic region. Gut Liver 5: 363-366, 2011

8. Candotti D and Allain JP: Transfusion-transmitted hepatitis B virus infection. J Hepatol 51: 798-809, 2009.

9. Hollinger FB: Hepatitis B virus infection and transfusion medicine: Science and the occult. Transfusion 48: 1001-1026, 2008.

10. Yeo W and Johnson PJ: Diagnosis, prevention and management of hepatitis $\mathrm{B}$ virus reactivation during anticancer therapy. Hepatology 43: 209-220, 2006.

11. Chevaliez S, Bouvier-Alias M, Laperche S, Hézode C and Pawlotsky JM: Performance of version 2.0 of the Cobas AmpliPrep/Cobas TaqMan real-time PCR assay for hepatitis B virus DNA quantification. J Clin Microbiol 48: 3641-3647, 2010.

12. Brind A, Jiang J, Samuel D, Gigou M, Feray C, Bréchot C and Kremsdorf D: Evidence for selection of hepatitis B mutants after liver transplantation through peripheral blood mononuclear cell infection. J Hepatol 26: 228-235, 1997.

13. Köck J, Theilmann L, Galle P and Schlicht HJ: Hepatitis B virus nucleic acids associated with human peripheral blood mononuclear cells do not originate from replicating virus. Hepatology 23: 405-413, 1996.

14. Loustaud-Ratti V, Wagner A, Carrier P, Marczuk V, Chemin I, Lunel F, Fouchard-Hubert I, Ahmed SS, Abergel A, Rousseau A, et al: Distribution of total DNA and cccDNA in serum and PBMCs may reflect the HBV immune status in HBsAg+ and HBsAg-patients coinfected or not with HIV or HCV. Clin Res Hepatol Gastroenterol 37: 373-383, 2013.

15. Roche B, Feray C, Gigou M, Roque-Afonso AM, Arulnaden JL, Delvart V, Dussaix E, Guettier C, Bismuth H and Samuel D: HBV DNA persistence 10 years after liver transplantation despite successful anti-HBS passive immunoprophylaxis. Hepatology 38: 86-95, 2003.

16. Umeda M, Marusawa H, Seno H, Katsurada A, Nabeshima M, Egawa H, Uemoto S, Inomata Y, Tanaka $\mathrm{K}$ and Chiba T: Hepatitis $B$ virus infection in lymphatic tissues in inactive hepatitis B carriers. J Hepatol 42: 806-812, 2005.

17. Budkowska A, Maillard P, Theret N, Groh F, Possehl C, Topilko A and Crainic R: Activation of the envelope proteins by a metalloproteinase enables attachment and entry of the hepatitis B virus into T-lymphocyte. Virology 237: 10-22, 1997.

18. El-Awady MK, Youssef SS, Omran MH, Tabll AA, El Garf WT and Salem AM: Soluble egg antigen of Schistosoma Haematobium induces $\mathrm{HCV}$ replication in $\mathrm{PBMC}$ from patients with chronic HCV infection. BMC Infect Dis 6: 91 , 2006.

19. Michalak TI: Occult persistence and lymphotropism of hepadnaviral infection: Insights from the woodchuck viral hepatitis model. Immunol Rev 174: 98-111, 2000.

20. Michalak TI, Mulrooney PM and Coffin CS: Low doses of hepadnavirus induce infection of the lymphatic system that does not engage the liver. J Virol 78: 1730-1738, 2004. 
21. Michalak TI, Pardoe IU, Coffin CS, Churchill ND, Freake DS Smith P and Trelegan CL: Occult lifelong persistence of infectious hepadnavirus and residual liver inflammation in woodchucks convalescent from acute viral hepatitis. Hepatology 29: 928-938, 1999.

22. Dan L, Lan Y, Shi Y, Zhang Y and Li Y: Study on hepatitis B virus replication in haematopoietic stem cell and its effect on the immune activity of haemopoietic stem cell. Chin J Infect Dis 28 : 144-149, 2010 (In Chinese).

23. Shi Y, Lan Y, Cao F, Teng Y, Li L, Wang F, Li J, Zhou J and Li Y: Infected hematopoietic stem cells and with integrated HBV DNA generate defective $\mathrm{T}$ cells in chronic $\mathrm{HBV}$ infection patients. J Viral Hepat 21: e39-e47, 2014.

24. Huang X, Lu D, Ji G, Sun Y, Ma L, Chen Z, Zhang L, Huang J and Yu L: Hepatitis B virus (HBV) vaccine-induced escape mutants of HBV S gene among children from Qidong area, China. Virus Res 99: 63-68, 2004.

25. Rong Q, Huang J, Su E, Li J, Li J, Zhang L and Cao K: Infection of hepatitis B virus in extrahepatic endothelial tissues mediated by endothelial progenitor cells. Virol J 4: 36, 2007.

26. Pham TN, Macparland SA, Coffin CS, Lee SS, Bursey FR and Michalak TI: Mitogen-induced upregulation of hepatitis $\mathrm{C}$ virus expression in human lymphoid cells. J Gen Virol 86: 657-666, 2005.
27. Kanda N, Tsuchida T and Tamaki K: Testosterone inhibits immunoglobulin production by human peripheral blood mononuclear cells. Clin Exp Immunol 106: 410-415, 1996.

28. Cai D, Nie H, Yan R, Guo JT, Block TM and Guo H: A southern blot assay for detection of hepatitis B virus covalently closed circular DNA from cell cultures. Methods Mol Biol 1030: 151-161, 2013.

29. Tai DI, Chung ZJ, Chen CL and Eng HL: Reappearance of HBsAg with compartmentalized different HBV strains in allograft versus PBMC of the recipient. J Gastroenterol 36: 200-205, 2001

30. Wong DK, Huang FY, Lai CL, Poon RT, Seto WK, Fung J, Hung IF and Yuen MF: Occult hepatitis B infection and HBV replicative activity in patients with cryptogenic cause of hepatocellular carcinoma. Hepatology 54: 829-836, 2011.

31. Bhargava A, Khan S, Panwar H, Pathak N, Punde RP, Varshney S and Mishra PK: Occult hepatitis B virus infection with low viremia induces DNA damage, apoptosis and oxidative stress in peripheral blood lymphocytes. Virus Res 153: 143-150, 2010.

32. Gerlich WH, Bremer C, Saniewski M, Schüttler CG, Wend UC, Willems WR and Glebe D: Occult hepatitis B virus infection: Detection and significance. Dig Dis 28: 116-125, 2010. 